\title{
Quality improvement and network externalities
}

J.J. Gabszewicz and F. Garcia

Discussion Paper 2005-64

Département des Sciences Économiques

de l'Université catholique de Louvain 


\title{
Quality improvement and network externalities
}

\author{
Jean J. Gabszewicz and Filomena Garcia*
}

January 9, 2006

\begin{abstract}
We analyse the optimal pricing choice of an incumbent firm that sells a good with network externalities and is threatened by the entry of a higher quality variant. In the framework of a vertical differentiation model, we find a necessary and sufficient condition under which quality improvement occurs as a result of this competition.

Keywords: Vertical product differentiation, network externalities, quality improvement. JEL Classification: L11, L12, L15.
\end{abstract}

${ }^{*}$ We thank Paolo Colla for his insightful comments on a previous version of this paper. We are grateful to Jacques Thisse and Xavier Wauthy for their helpful comments and suggestions. This paper presents research results of the Belgian Program on Interuniversity Poles of Attraction initiated by the Belgian State, Prime Minister's Office, Science Policy Programming. The scientific responsibility is assumed by the authors.Filomena Garcia thanks the financial support of Fundaçao Gulbenkian and CORE. 


\section{Introduction}

In this paper, we analyze a network industry in which an incumbent faces potential competition by a high quality brand. The incumbent benefits from the size of its installed base and decides whether or not to bar the entry of the higher quality brand and consequently, whether or not quality improvement takes place. The aim of this paper is to identify a necessary and sufficient condition under which quality improvements are spontaneously introduced, in spite of the existence of network effects.

It is frequently argued that the presence of network effects in an industry slows down technological progress. This occurs because consumers tend to prefer a good that is already in the market with an installed base rather than a new product without installed base, even if this product results from a less expensive technology. In this case, as argued by Shy (1996), the speed of technology adoption differs from the speed of technology innovation. We examine an analogous question for the case of quality innovation: in the presence of network effects, does the adoption path of higher quality goods differ from their innovation path? Clearly network effects should dampen the willingness of consumers to consume a new, higher quality product, simply because the existing one, even when of smaller quality, does benefit from the installed base. The entrant should provide a new brand whose quality sufficiently exceeds the quality of the old one in order to compensate this dampening effect, and induce consumers to switch to the better variant.

In order to understand the trade off between higher quality and network effect, we develop a two-stage business model in which an incumbent sells in the first period a certain good whose characteristics include the fact that consumers buying it in the second period may enjoy network externalities. We introduce heterogeneity in consumer's valuation for the goods in a vertical differentiation model and analyze the optimal behavior of an incumbent when a new product of higher quality becomes available in the second period. The

main difference from traditional models of vertical product differentiation is the presence of network effects. The consumers are not unanimous in their preferences for the high quality good, even when prices are equal. Due to the network externality, at equal prices, some agents may prefer to exploit the network effect by buying a low quality good, rather than enjoying the benefits 
of a higher quality one ${ }^{1}$. We identify a sufficient and necessary condition under which the incumbent prefers to accommodate the higher quality brand in equilibrium rather than barring its entry. This condition says that the intensity of network effects on consumers' preferences should not exceed twice the differential of intrinsic qualities existing between the two variants.

It is important to highlight the kind of goods that our analysis comprehends. As mentioned above, we consider a two stage model where the network takes one period of time to become effective. We consider therefore a delayed network effect. ${ }^{2}$ Also we assume that agents buy only in one period and cannot delay consumption. Our analysis is, in particular, appropriate for reputation goods, or goods which require a learning period. For instance, consider the market for a reputation good when reputation increases with the size of its market. The initial buyers of such a good spread information about how they enjoy its consumption, and often create a core of fans who praise its quality and virtues. The set of consumers who buy the good can be viewed as a network, improving the utility of its potential consumers and thereby the potential profits' opportunities of the firm selling the good. This is the case of several products resulting from recent innovation, and whose characteristics can only be revealed by direct consumption. The larger the set of initial buyers, the larger the utility subsequent buyers expect to obtain. Also for many goods, the size of the initial network of buyers determines the availability of complementary services the seller would be willing to develop around the variant which is initially supplied. Examples are: a new durable good and the number of shops which increases with the number of its consumers; a new machine and the number of its components when they are available to subsequent buyers, like in the case of a computer whose number of compatible programs increases with the number of its initial buyers; or, more generally, any good whose quality increases through time when the number of its buyers increases. In all such cases, the utility of the subsequent buyers for the good increases with the network size of its initial buyers. Notice however that such product improvements or reputation effects need some period of time to be finalized, creating a time lag between the creation of the network, and its effect on the

\footnotetext{
${ }^{1}$ The idea of analysing network effects in the framework of a vertically differentiated industry is not new (see, in particular, Baake and Boome (1999) and Bental and Spiegel (1995).

${ }^{2}$ The study of network externalities has been introduced for the first time in Rohlfs (1974).
} 
utility of subsequent buyers.

The problem of the trade off between technology improvement and network effect has been treated previously by several authors. Farrell and Saloner (1986), Katz and Shapiro (1992), Shy (1996) and Fudenberg and Tirole (2000) are all concerned with the problem of quality improvement. However, they do not use the vertical differentiation model to represent how the trade off between technology improvement and network effect operates. ${ }^{3}$ The above authors all assume that consumers have the same preferences. ${ }^{4}$ This implies that as soon as the new quality becomes available all consumers (or none) adopt it, depending on the magnitude of the network effect at the time of innovation. By contrast, we assume in our approach that consumers are heterogeneous. Specifically, this heterogeneity allows that, at identical prices, some consumers prefer the old technology with an installed base and lower quality, while others prefer the new technology without installed base. The individual preferences of consumers in the vertical differentiation model rely on a small number of parameters capturing the essentials of the trade off between network effects and quality. This is the reason why we are able to identify precisely how the optimal strategies of the incumbent are depending on these parameters and, beyond that, when it is optimal (for him) to accommodate entry and open the door for quality improvement. There are several other significant differences between these models and ours. All these papers consider an infinite horizon model in which a new technology becomes available at a certain defined period, while we assume initially a two-period model and show that the conclusions obtained can be extended to an infinite horizon. Shy (1996) models the result of technology improvement as an increase in the stand-alone value. With this respect, Shy's approach is close to ours even though he does not take into account the consequences of this improvement on prices and,

\footnotetext{
${ }^{3}$ Baake and Boom (1999) and Bental and Spiegel (1995) have also combined the use of a vertical product differentiation model with network externalities. However, Baake and Boom (1999) focus on compatibility decisions, without addressing the quality improvement problem. Similarly Bental and Spiegel (1995) analyse the market coverage issue when network effects are present in a static framework. The closest approach to ours is Gabszewicz, Pepall and Thisse (1992), who examine the entry problem when there are switching costs in a vertical product differentiation context.

${ }^{4}$ In fact, Fudenberg and Tirole (2000) assume the existence of two types of consumers; however, they are homogeneous in their preferences for the technological improvement and differ only in their stand-alone values.
} 
accordingly, the market participation constraint is not active. ${ }^{5}$ Furthermore, as stated above, consumers are assumed to be homogeneous in their tastes for quality improvement. Katz and Shapiro (1992) model technological improvement through a decrease in production costs while we assume a higher stand-alone value for the new product; they analyze the pricing strategies and the timing of product introduction. Their findings are the following: when technologies are compatible, pricing is the result of a Bertrand game with differentiated costs since technological progress reduces the entrant's cost. When technologies are incompatible the incumbent sets his price so as to make consumers indifferent between buying immediately upon arrival in the market, or delaying their purchase until the entry of the new technology. The incumbent is never able to deter entry if the opponent sells a compatible product. On the contrary, if the new product is incompatible, entry deterrence is possible. Therefore, the incumbent can deter entry with certainty by denying the entrant the possibility to sell a compatible product. In our model, entry deterrence is obtained through the level of prices set in initial periods, rather than through the compatibility decision. Farrell and Saloner (1986) analyze the possibility that the incumbent prevents entry by the rival through predatory pricing; however they do not discuss the conditions under which it arises. Fudenberg and Tirole (2000) develop a model of limit pricing based on the idea that the installed base of a network good can fill a preemptive role similar to that of investment in physical capacity. In their model a sequence of potential entrants threatens the incumbent monopoly power and leads to possible entry deterrence strategy. If entry occurs, all consumers prefer the improved good and this drives the price of the incumbent to the point where he is indifferent between deterring entry or not. In our case technological progress is modeled by the creation of a new product with higher quality but a certain degree of substitutability. Price competition does not drive the incumbent's profit to the point where he is indifferent between deterring entry or not, because goods are vertically differentiated. Also, in Fudenberg and Tirole (2000) entry deterrence is always possible due to the existence of an entry cost. In our model,

\footnotetext{
${ }^{5}$ Shy (1996) considers technologies to be supplied at competitive prices and accordingly he does not analyse price decisions. He also treats the possibility that a monopolist produces the technology and its improvements, however he does not consider the possibility of a threatening opponent.
} 
there is no entry cost and thus entry deterrence is necessarily the result of the pricing policy pursued during initial periods.

We describe the model in section 2. Section 3 analyses when this deterrence of the quality improvement does not take place. Some final remarks and avenues for further research are gathered in the conclusion.

\section{The model}

Consider the market for a good with positive network externalities, say good 1, sold in period 1 by a monopolist at constant average cost normalized to 0 . The monopolist is assumed to be protected against entry by a patent during period 1 , but free entry is assumed to be authorized in the next period. Moreover, we assume that the life cycle of product 1 does not extend beyond the end of period 2. In each period there is a cohort of consumers, indexed by a parameter $v$ uniformly distributed on $[0,1]$, entering the market. In period 1 , these consumers, who are assumed to buy at most one unit of the good, obtain utility only from its stand-alone value: the network effect generated by good 1 takes one period of time to become effective. Thus consumers who acquire the good in the first period do not benefit from the network externality due to the delay in the network effect. Consequently, the utility for consumer $v$ in period 1 for buying good 1 is simply given by $\beta_{1} v-p_{11}$, with $\beta_{1}>0$ measuring the quality of product 1 , and $p_{11}$ the price set by the incumbent in period 1 .

In the second period, a new, higher intrinsic quality good, say good 2, becomes available for sale by an entrant, firm 2. We shall also assume a zero average cost for producing good 2. The stand alone value of good 2 for consumer $v$ is given by $\beta_{2} v$. We assume throughout that $\beta_{2} \geq 4 \beta_{1}$. The utility of type $v$ consumer in period 2 for buying product 2 at price $p_{22}$ is given by $\beta_{2} v-p_{22}$. Notice that even if we conduct the analysis as if product 2 does not generate network effects in the subsequent period, we shall later explain that this assumption does not affect the conclusion of our analysis.

Now, the cohort of consumers entering the market in period 2 and buying good 1 not only enjoy its stand alone value, but also its network value, generated in the previous period. We assume that all consumers value the network effect in the same way through a parameter $\alpha$. Consequently, the utility of buying product 1 in period 2 for consumer $v$ writes as $\beta_{1} v+\alpha D_{11}\left(p_{11}\right)-p_{12}$, 
with $p_{12}$ denoting the price of good 1 in period 2 and $D_{11}\left(p_{11}\right)$ the size of first period sales. Thus, in period 2, competition takes place between two firms: the incumbent, firm 1 , selling product 1 and enjoying its network effects resulting from its first period sales and the entrant, firm 2, selling a higher intrinsic quality product. Define the quality index of product $i$ as the utility obtained by consumer of type $v=1$ at zero prices when he consumes product $i$. Accordingly, the quality index of good 1 in period 2 is given by $\beta_{1}+\alpha D_{11}\left(p_{11}\right)$ while the quality index of good 2 is equal to $\beta_{2}$.

In the first period, the incumbent is alone in the market and sells only good 1. A consumer $v$ will buy if $\beta_{1} v \geq p_{11}$. The demand is given by:

$$
D_{11}\left(p_{11}\right)=1-\frac{p_{11}}{\beta_{1}} .
$$

The monopolist serves the market in the interval $\left[\frac{p_{11}}{\beta_{1}}, 1\right]$. The profit of the incumbent in the first period is given by

$$
\pi_{11}\left(p_{11}\right)=p_{11}\left(1-\frac{p_{11}}{\beta_{1}}\right) .
$$

The incumbent anticipates the entry by firm 2 . The goods sold by firm 1 and 2 are exogenously differentiated in quality, but also endogenously differentiated, due to the first mover advantage of firm 1 . This advantage allows the incumbent to manipulate the quality of its product sold in period 2 through the choice of its first period price. In the first period, the incumbent sets price $p_{11}$ and, in the second period, he competes in prices with the entrant. In the second period, we assume that these prices are determined at a price equilibrium of the corresponding game. However, firm 1, anticipating entry by firm 2 , is able to control, through the first period price $p_{11}$, the competitive conditions in the market in period 2: depending on whether $p_{11}$ is high or low, few or many consumers buy the good in period 1, and the resulting network created in the first period is small or large.

Several elements can influence consumers' choice in the second period: the quality differential between the two variants, $\beta_{2}-\beta_{1}$, the intensity of the network effect $\alpha$, the pricing policy $p_{11}$ of the incumbent in the first period and, finally, the prices $p_{12}$ and 22 chosen by both firms in the second period. Traditional models of vertical differentiation are characterized by the fact that at identical prices all consumers rank in the same way the different qualities. 
This property is no longer satisfied in the presence of network externalities. This occurs because the network externality brings a different source of quality differentiation that is independent of the type of consumer. Low types are induced to buy product 1 .

Denote by $v_{1}\left(p_{12}, p_{22} ; p_{11}\right)$ the consumer who is indifferent between buying good 1 or good 2 in the second period. The value $v_{1}\left(p_{12}, p_{22} ; p_{11}\right)$ is the solution to the equation

$$
\beta_{1} v+\alpha D_{11}\left(p_{11}\right)-p_{12}=\beta_{2} v-p_{22},
$$

which implies that $v_{1}\left(p_{12}, p_{22} ; p_{11}\right)=\frac{p_{22}-p_{12}+\alpha D_{11}\left(p_{11}\right)}{\beta_{2}-\beta_{1}}$. If $\alpha$ is taken to be 0 , the value $v_{1}\left(p_{12}, p_{22} ; p_{11}\right)$ corresponds to the indifferent consumer in the traditional model of vertical differentiation. In the present case, the indifferent consumer is shifted by $\frac{\alpha D_{11}\left(p_{11}\right)}{\beta_{2}-\beta_{1}}$, a measure of the relative weight of the two sources of quality differentiation. The consumer indifferent between buying good 1 or not buying at all is given by $v_{2}\left(p_{12}\right)$, which is the solution to

$$
\beta_{1} v+\alpha D_{11}\left(p_{11}\right)-p_{12}=0 .
$$

namely, $v_{2}\left(p_{12} ; p_{11}\right)=\frac{p_{12}-\alpha D_{11}\left(p_{11}\right)}{\beta_{1}}$.

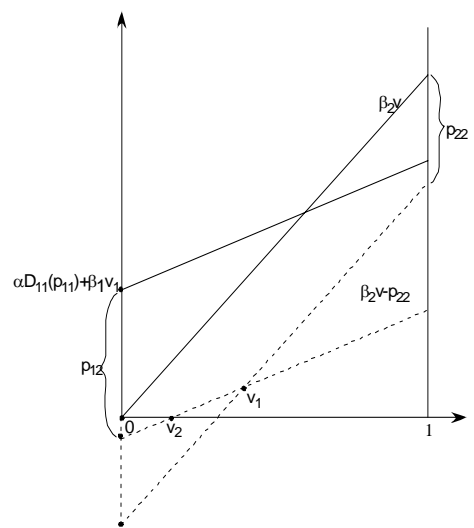

Figure 1: The marginal consumers

For both demands to be strictly positive and smaller than 1 we must have that $0<v_{2}<v_{1}<1$, which is equivalent to

$$
\begin{aligned}
p_{22}-p_{12}+\alpha D_{11}\left(p_{11}\right)-\left(\beta_{2}-\beta_{1}\right) & <0 \\
p_{12} \beta_{2}-p_{22} \beta_{1}-\alpha D_{11}\left(p_{11}\right) \beta_{2} & <0 \\
p_{12}-\alpha D_{11}\left(p_{11}\right) & >0
\end{aligned}
$$


Within the area of prices $\left(p_{12}, p_{22}\right)$ defined by the previous inequalities, we have that the demand in period 2 for good 1 is given by

$$
D_{12}\left(p_{12}, p_{22} ; p_{11}\right)=\frac{p_{22}-p_{12}+\alpha D_{11}\left(p_{11}\right)}{\beta_{2}-\beta_{1}}-\frac{p_{12}-\alpha D_{11}\left(p_{11}\right)}{\beta_{1}},
$$

while the demand for good 2 obtains as

$$
D_{22}\left(p_{12}, p_{22} ; p_{11}\right)=1-\frac{p_{22}-p_{12}+\alpha D_{11}\left(p_{11}\right)}{\beta_{2}-\beta_{1}} .
$$

Condition 5 guarantees that there exist some consumers who buy neither of the two products in the market: the market is uncovered. When the reverse inequality holds, all consumers buy one of the products: the market is covered. In that case, demands are given by

$$
\begin{aligned}
& D_{12}\left(p_{12}, p_{22} ; p_{11}\right)=\frac{p_{22}-p_{12}+\alpha D_{11}\left(p_{11}\right)}{\beta_{2}-\beta_{1}}, \\
& D_{22}\left(p_{12}, p_{22} ; p_{11}\right)=1-\frac{p_{22}-p_{12}+\alpha D_{11}\left(p_{11}\right)}{\beta_{2}-\beta_{1}} .
\end{aligned}
$$

Notice that in the traditional model of vertical differentiation, with consumer types distributed over the interval $[0,1]$, the market would never be covered at positive prices in a duopoly industry. This is so because the lowest-type consumer only buys if the price is set to be zero: his valuation is indeed equal to zero. When network effects are present, the consumer type zero buys even at positive prices, in order to benefit from the network. It is therefore necessary to distinguish whether after entry, demands correspond to that of a covered, or uncovered, market. Reminding that $D_{11}\left(p_{11}\right)=\left(1-\frac{p_{11}}{\beta_{1}}\right)$, the corresponding second period profits for both firms obtain as

$$
\begin{aligned}
& \pi_{12}\left(p_{12}, p_{22}\right)=p_{12}\left[\frac{p_{22}+\alpha\left(1-\frac{p_{11}}{\beta_{1}}\right)-p_{12}}{\beta_{2}-\beta_{1}}-\max \left\{\frac{p_{12}-\alpha\left(1-\frac{p_{11}}{\beta_{1}}\right)}{\beta_{1}}, 0\right\}\right] \\
& \pi_{22}\left(p_{12}, p_{22}\right)=p_{22}\left[1-\frac{p_{22}+\alpha\left(1-\frac{p_{11}}{\beta_{1}}\right)-p_{12}}{\beta_{2}-\beta_{1}}\right] .
\end{aligned}
$$

For the quality improvement resulting from the introduction of good 2 to take place, it is needed that the marginal consumer $v_{1}$ corresponding to the optimal price policy of the incumbent, be strictly smaller than 1, i.e. $p_{22}^{*}-p_{12}^{*}+\alpha D_{11}\left(p_{11}^{*}\right)<\beta_{2}-\beta_{1}$, with the pair $\left(p_{12}^{*}, p_{22}^{*}\right)$ denoting equilibrium values of prices in the second period and $p_{11}^{*}$ the optimal price in period 1 . 
The subsequent analysis aims at identifying a necessary and sufficient condition to allow product improvement.

\section{Equilibrium analysis}

In this section we analyze the general case in order to identify the conditions under which quality improvement does actually take place. As mentioned above, the incumbent is able to drive the second period market equilibrium through its choice of first period price. In other words, the size of the network that he chooses to constitute is determinant in the market conditions that the entrant faces. Moreover, the incumbent might be interested in practising an aggressive strategy to limit entry by the opponent (the so-called limit pricing strategy). Starting with the second period market subgame, two possibilities might be pursued by the incumbent: either to allow entry, or to deter it. ${ }^{6}$

\subsection{Limit pricing}

We examine first the entry deterrence outcome. In order to deter entry, firm 1 must quote the price

$$
p_{12}\left(p_{22}\right)=\alpha\left(1-\frac{p_{11}}{\beta_{1}}\right)-\left(\beta_{2}-\beta_{1}\right)+p_{22}
$$

which cancels demand of firm 2 when it quotes a price equal to $p_{22}$. Entry deterrence occurs when $D_{22}\left(p_{12}, p_{22}\right)=0$ even if $p_{22}=0$. Then, the candidate equilibrium is the pair of prices $\left(p_{12}^{L}, p_{22}^{L}\right)$ defined by

$$
\begin{aligned}
& p_{12}^{L}=\alpha\left(1-\frac{p_{11}}{\beta_{1}}\right)-\left(\beta_{2}-\beta_{1}\right) \\
& p_{22}^{L}=0 .
\end{aligned}
$$

We immediately notice that, whatever the price $p_{11}$ in $\left[0, \beta_{1}\right]$ selected in the first period, $p_{12}^{L}$ is smaller than 0 when $\alpha<\beta_{2}-\beta_{1}$. Therefore no limit pricing strategy exists for the incumbent in this area of the parameters: when $\alpha$ is small relative to the difference in the intrinsic qualities, the cost of entry

\footnotetext{
${ }^{6}$ The reverse possibility where the entrant forces exit of the incumbent cannot arise. To force the exit of the incumbent the entrant should quote a price such that, even when $p_{12}=0$, demand of firm 1 could not be positive. However, even quoting $p_{22}=0, D_{12}>0$.
} 
deterrence is prohibitive for the incumbent. Consequently, when $\alpha<\beta_{2}-\beta_{1}$, whatever the price $p_{11}$ selected by the incumbent in period 1 , he is constrained to accommodate entry in period 2.

On the contrary, when $\alpha \geq \beta_{2}-\beta_{1}$, it is possible to practise limit pricing, which entails a second period profit of $\alpha\left(1-\frac{p_{11}}{\beta_{1}}\right)-\left(\beta_{2}-\beta_{1}\right)$. The optimal choice of the incumbent for first period price is then given by the solution to the following optimization problem:

$$
\max _{p_{11}} \Pi_{\text {total }}\left(p_{11}\right)=p_{11}\left(1-\frac{p_{11}}{\beta_{1}}\right)+\alpha\left(1-\frac{p_{11}}{\beta_{1}}\right)-\left(\beta_{2}-\beta_{1}\right)
$$

It is easily shown that the optimal admissible value for $p_{11}$ is zero. ${ }^{7}$ Thus, at the optimal first-period strategy, the incumbent obtains a total profit equal to $\alpha-\left(\beta_{2}-\beta_{1}\right)$ when using his limit pricing strategy in period 2. We now compute the incumbent's optimal price profile for the situation in which both firms are active in the market.

\subsection{Entry accommodation}

In traditional models of vertical product differentiation, with types distributed over the $[0,1]$ interval, the market is always uncovered. In the presence of network externalities it is however necessary to discuss whether the optimal solution is to cover the market or not, since the existence of the network gives a positive utility to the lowest type even at positive prices. The distinction between a covered or uncovered market is important since demands are defined differently in one case or the other. This can be observed in Figure 2.

\footnotetext{
${ }^{7}$ The total profit function is concave and attains its maximum at $p_{11}=\frac{1}{2}\left(\beta_{1}-\alpha\right)$. If $\beta_{2}>4 \beta_{1}$, as assumed in the model, the above value for $p_{11}$ is negative and therefore, when $\beta_{2}-\beta_{1}<\alpha$, the optimal value obtains at $p_{11}=0$.
} 

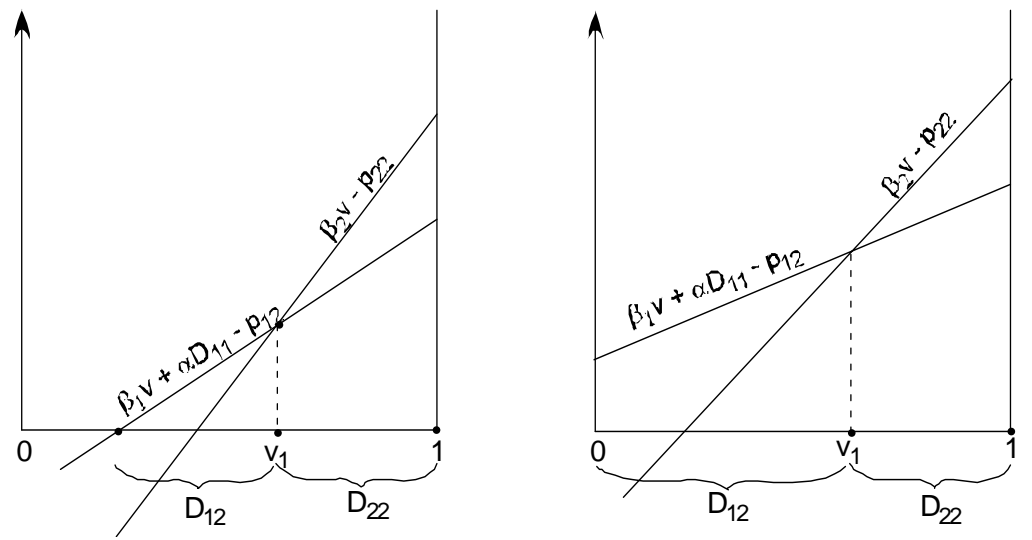

Figure 2: Covered and uncovered market.

Consider first a pair of prices such that both firms are active in the market in period 2 but the market is uncovered. In this alternative, profits are given by:

$$
\begin{aligned}
& \pi_{12}\left(p_{12}, p_{22}\right)=p_{12}\left(\frac{p_{22}+\alpha\left(1-\frac{p_{11}}{\beta_{1}}\right)-p_{12}}{\beta_{2}-\beta_{1}}-\frac{p_{12}-\alpha\left(1-\frac{p_{11}}{\beta_{1}}\right)}{\beta_{1}}\right) \\
& \pi_{22}\left(p_{12}, p_{22}\right)=p_{22}\left(1-\frac{p_{22}+\alpha\left(1-\frac{p_{11}}{\beta_{1}}\right)-p_{12}}{\beta_{2}-\beta_{1}}\right) .
\end{aligned}
$$

The following necessary and sufficient conditions must be satisfied at an interior equilibrium,

$$
\begin{aligned}
& \frac{\partial \pi_{12}}{\partial p_{12}}=\frac{\beta_{1} p_{22}-2 p_{12} \beta_{2}+\alpha\left(1-\frac{p_{11}}{\beta_{1}}\right) \beta_{2}}{\beta_{1}\left(\beta_{2}-\beta_{1}\right)}=0 \\
& \frac{\partial \pi_{22}}{\partial p_{22}}=\frac{\beta_{2}-\beta_{1}-2 p_{22}+p_{12}-\alpha\left(1-\frac{p_{11}}{\beta_{1}}\right)}{\beta_{2}-\beta_{1}}=0,
\end{aligned}
$$

with resulting candidate equilibrium prices

$$
\begin{aligned}
& p_{12}^{*}=\frac{\beta_{1}\left(\beta_{2}-\beta_{1}\right)+\alpha\left(1-\frac{p_{11}}{\beta_{1}}\right)\left(2 \beta_{2}-\beta_{1}\right)}{4 \beta_{2}-\beta_{1}}, \\
& p_{22}^{*}=\beta_{2} \frac{2\left(\beta_{2}-\beta_{1}\right)-\alpha\left(1-\frac{p_{11}}{\beta_{1}}\right)}{4 \beta_{2}-\beta_{1}} .
\end{aligned}
$$


The price $p_{12}$ is always positive while a sufficient condition for the price $p_{22}$ to be positive is $\alpha \leq 2\left(\beta_{2}-\beta_{1}\right)$. The demands at the interior candidate equilibrium are

$$
\begin{aligned}
& D_{12}\left(p_{12}^{*}, p_{22}^{*}\right)=\beta_{2} \frac{\left(2 \beta_{2}-\beta_{1}\right) \alpha\left(1-\frac{p_{11}}{\beta_{1}}\right)+\left(\beta_{2}-\beta_{1}\right) \beta_{1}}{\beta_{1}\left(4 \beta_{2}-\beta_{1}\right)\left(\beta_{2}-\beta_{1}\right)} \\
& D_{22}\left(p_{12}^{*}, p_{22}^{*}\right)=\beta_{2} \frac{2\left(\beta_{2}-\beta_{1}\right)-\alpha\left(1-\frac{p_{11}}{\beta_{1}}\right)}{\left(4 \beta_{2}-\beta_{1}\right)\left(\beta_{2}-\beta_{1}\right)} .
\end{aligned}
$$

The demand $D_{12}\left(p_{12}^{*}, p_{22}^{*}\right)$ is always positive while a sufficient condition for $D_{22}\left(p_{12}^{*}, p_{22}^{*}\right)$ to be positive is again $\alpha \leq 2\left(\beta_{2}-\beta_{1}\right)$. Furthermore we must check that $D_{12}\left(p_{12}^{*}, p_{22}^{*}\right)+D_{22}\left(p_{12}^{*}, p_{22}^{*}\right)<1$ which holds if and only if

$$
\beta_{2} \frac{3 \beta_{1}+2 \alpha\left(1-\frac{p_{11}}{\beta_{1}}\right)}{\left(4 \beta_{2}-\beta_{1}\right) \beta_{1}}<1 .
$$

To these prices and demands correspond the interior candidate equilibrium profits,

$$
\begin{aligned}
& \pi_{12}\left(p_{12}^{*}, p_{22}^{*}\right)=\frac{\beta_{2}\left(\beta_{1}\left(\beta_{2}-\beta_{1}\right)+\alpha\left(1-\frac{p_{11}}{\beta_{1}}\right)\left(2 \beta_{2}-\beta_{1}\right)\right)^{2}}{\left(4 \beta_{2}-\beta_{1}\right)^{2}\left(\beta_{2}-\beta_{1}\right) \beta_{1}} \\
& \pi_{22}\left(p_{12}^{*}, p_{22}^{*}\right)=\beta_{2}^{2} \frac{\left(2\left(\beta_{2}-\beta_{1}\right)-\alpha\left(1-\frac{p_{11}}{\beta_{1}}\right)\right)^{2}}{\left(4 \beta_{2}-\beta_{1}\right)^{2}\left(\beta_{2}-\beta_{1}\right)} .
\end{aligned}
$$

We observe that the interior candidate price equilibrium is a function of the price $p_{11}$ selected by the incumbent in period 1 , which determines the network size in period 2 .

Now assume that interior candidate equilibrium prices lead to a covered market. The profits are then given by:

$$
\begin{aligned}
& \pi_{12}\left(p_{12}, p_{22} ; p_{11}\right)=p_{12}\left(\frac{p_{22}+\alpha\left(1-\frac{p_{11}}{\beta_{1}}\right)-p_{12}}{\beta_{2}-\beta_{1}}\right) \\
& \pi_{22}\left(p_{12}, p_{22} ; p_{11}\right)=p_{22}\left(1-\frac{p_{22}+\alpha\left(1-\frac{p_{11}}{\beta_{1}}\right)-p_{12}}{\beta_{2}-\beta_{1}}\right) .
\end{aligned}
$$


The first order conditions imply that at an interior candidate price equilibrium:

$$
\begin{aligned}
\frac{p_{22}-2 p_{12}+\alpha\left(1-\frac{p_{11}}{\beta_{1}}\right)}{\left(\beta_{2}-\beta_{1}\right)} & =0 \\
\frac{\left(\beta_{2}-\beta_{1}\right)+\left(p_{12}-2 p_{22}\right)-\alpha\left(1-\frac{p_{11}}{\beta_{1}}\right)}{\left(\beta_{2}-\beta_{1}\right)} & =0,
\end{aligned}
$$

with corresponding prices,

$$
\begin{gathered}
p_{22}=\frac{1}{3}\left(2\left(\beta_{2}-\beta_{1}\right)-\alpha\left(1-\frac{p_{11}}{\beta_{1}}\right)\right), \\
p_{12}=\frac{1}{3}\left(\alpha\left(1-\frac{p_{11}}{\beta_{1}}\right)+\beta_{2}-\beta_{1}\right)
\end{gathered}
$$

and equilibrium profits given by

$$
\begin{aligned}
& \pi_{22}\left(p_{11}\right)=\frac{1}{9} \frac{\left(2\left(\beta_{2}-\beta_{1}\right)-\alpha\left(1-\frac{p_{11}}{\beta_{1}}\right)\right)^{2}}{\beta_{2}-\beta_{1}}, \\
& \pi_{12}\left(p_{11}\right)=\frac{1}{9} \frac{\left(\alpha\left(1-\frac{p_{11}}{\beta_{1}}\right)+\beta_{2}-\beta_{1}\right)^{2}}{\beta_{2}-\beta_{1}} .
\end{aligned}
$$

In order to identify the optimal profile of prices for the incumbent, we have now to analyze his first period optimal strategy both for the case of covered and uncovered second-period market. We have assumed in the model that $\beta_{2}>4 \beta_{1}$. As it is shown in the proof of the following lemma, this assumption gives a sufficiently high intrinsic quality differential between the two goods in order to induce the incumbent to create the largest network in the first period by quoting a zero price.

Lemma 3.1 When $\beta_{2}-\beta_{1}<\alpha$ and the incumbent accommodates entry of firm 2, its optimal first period price is given by $p_{11}^{*}=0$.

Proof: See the appendix.

From Lemma 4.1, it follows that, under entry accommodation, the incumbent always chooses to maximize his installed base in the first period by quoting price zero, both in the case of covered and uncovered market. It is easy to see however, that in the same domain, the condition (10) guaranteeing the existence of an uncovered market at equilibrium prices in period 2, is never met when $p_{11}=0$. Thus, we can rule out the possibility that the incumbent would drive the equilibrium path to an equilibrium with an uncovered market in stage 2 . Thus, under entry accommodation, only the total profit corresponding to a zero price in period 1 and the market coverage solution in 
period 2 has to be taken into account by the incumbent when deciding whether or not to deter entry, namely

$$
\Pi_{\text {total }}(0)=\frac{1}{9} \frac{\left(\alpha+\beta_{2}-\beta_{1}\right)^{2}}{\beta_{2}-\beta_{1}} .
$$

\subsection{Total profit comparisons}

Now we can compare the total profits under limit pricing and entry accommodation, always having in mind to identify the optimal pricing profile of the incumbent. This comparison has to be performed only when $\alpha \in\left[\beta_{2}-\beta_{1}, 2\left(\beta_{2}-\beta_{1}\right)\right]$. Indeed, when $\alpha<\beta_{2}-\beta_{1}$, no limit pricing is possible while, when $\alpha \geq$ $2\left(\beta_{2}-\beta_{1}\right)$, no accommodation is possible at equilibrium since demand of firm 2 is negative at equilibrium prices. It is easy to see that when $\alpha \in$ $\left[\beta_{2}-\beta_{1}, 2\left(\beta_{2}-\beta_{1}\right)\right]$,

$$
\Pi_{\text {total }}(0)=\frac{1}{9} \frac{\left(\alpha+\beta_{2}-\beta_{1}\right)^{2}}{\beta_{2}-\beta_{1}}>\alpha-\left(\beta_{2}-\beta_{1}\right),
$$

where the last term of this inequality represents the total profit for the entry deterrence strategy: in the domain $\alpha \in\left[\beta_{2}-\beta_{1}, 2\left(\beta_{2}-\beta_{1}\right)\right]$, the incumbent gets a higher total profit by accommodating entry than by practising a limit pricing strategy (see Figure 3).

Consequently, for all $\alpha \in\left[0,2\left(\beta_{2}-\beta_{1}\right)\right]$, the optimal strategy for the incumbent consists in accommodating entry. Thus we conclude:

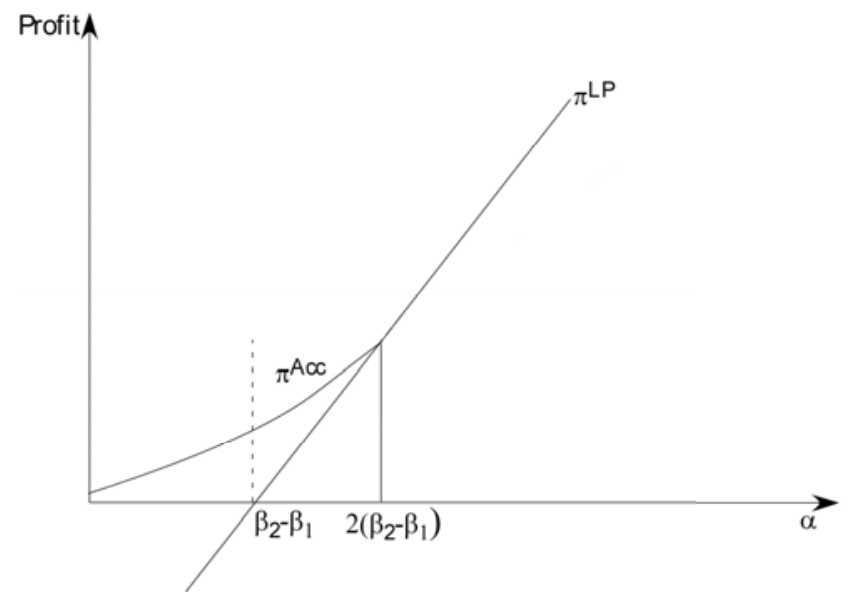

Figure 3: Profits under entry deterrence and entry accommodation. 
Proposition 3.1 A necessary and sufficient condition for quality improvement is

$$
\alpha \leq 2\left(\beta_{2}-\beta_{1}\right) .
$$

The intensity of the network effect in the preferences of the consumers should not be too large compared with the intrinsic quality differential between the two variants: otherwise entry deterrence would necessarily take place. In fact, when $\alpha \geq 2\left(\beta_{2}-\beta_{1}\right)$, the difference between the network effect intensity $\alpha$ and the stand-alone values differential $\beta_{2}-\beta_{1}$, makes it more advantageous to the incumbent to prevent both products to compete with each other in the second-period market. The size of the network effect amplifies the intrinsic quality of the standard variant sold in period 1 to such an extent that it becomes the product with the highest quality index in period 2. It is easy to anticipate that lowering the amplitude of the network effect below the differential of the intrinsic quality parameters can make the use of the entry deterrence strategy less attractive, and give room for quality improvement adoption.

This result relates directly to the main findings in Garcia (2005). When a monopolist sells a good with network externalities and has the possibility of introducing a higher quality brand in the market, Garcia (2005) shows that quality improvement takes place if and only if the network intensity, $\alpha$, is smaller than the quality differential, $\beta_{2}-\beta_{1}$. The threshold is thus higher when the new quality is sold by a rival than if it is sold by the monopolist himself. Quality improvement is more likely under competition than under monopoly and the reason is that, for some values of the network effect, it is too costly to deter the entry of a rival. On the contrary, under monopoly, it is costless to deter the introduction of the high quality.

The above analysis has been conducted assuming that the life cycle of good 1 has two periods, and that good 2 would not generate network externalities in subsequent periods. The first assumption guarantees that the horizon of the incumbent does not extend beyond period 2. Otherwise he would have to take into account all subsequent periods when defining his optimal pricing strategy. The resulting increase in complexity would not be compensated by the development of new insights in the problem. We will now argue that the second assumption does not play any role in our main conclusion. When $\alpha>2\left(\beta_{2}-\beta_{1}\right)$, the incumbent practises limit pricing, which entails a zero 
demand for firm 2 and, accordingly, no network can be constituted having effect in subsequent periods. If $\alpha \leq 2\left(\beta_{2}-\beta_{1}\right)$, the incumbent is willing to accommodate entry when the rival sells a good without network effect in the subsequent periods. If there would exist network effects related to this second good, the rival would certainly quote in the subsequent periods a lower price in period 2 than the equilibrium price without network effects which we have identified above. In particular he could possibly set a price equal to zero in order to create the largest installed base for period 3. Since the incumbent accommodates entry in the latter situation, he will a fortiori accommodate entry when his opponent can constitute a network. Thus, the condition $\alpha \leq$ $2\left(\beta_{2}-\beta_{1}\right)$ remains necessary and sufficient for quality improvement. Notice that if the condition $\alpha>2\left(\beta_{2}-\beta_{1}\right)$ is satisfied, the entry of product 2 is barred and firm 1 remains a monopolist over periods 1 and 2, disappearing at the end of the latter. Assuming that the barred product can no longer enter the market, product 3 is the only candidate for sale in period 3 . When the condition $\alpha>2\left(\beta_{4}-\beta_{3}\right)$ also holds, firm 3 remains a monopolist over periods 3 and 4 , and disappears at the end of period 3 . This reasoning can be pursued for periods beyond period 4, as long as the condition for entry deterrence is satisfied. The market structure is a sequence of monopolies with effective quality improvement arising every two periods due to the bounded life cycle of the variants.

\section{Welfare Comparisons}

It is interesting to identify the circumstances under which the use of an accommodating strategy pareto-dominates the practise of limit pricing. This comparison is only meaningful in the domain of parameters in which the incumbent disposes of both possibilities, namely when $\alpha \in\left(\beta_{2}-\beta_{1}, 2\left(\beta_{2}-\beta_{1}\right)\right)$. Remind that the optimal first period strategy of the incumbent always consists in quoting $p_{11}=0$. Accordingly, under limit pricing, the total surplus $W^{L P}$ over the two periods writes as

$$
\begin{aligned}
W^{L P} & =C S_{1}^{L P}+C S_{2}^{L P}+\Pi_{1}^{L P}+\Pi_{2}^{L P}= \\
& =\int_{0}^{1}\left(\beta_{1} v\right) d v+\int_{0}^{1}\left(\beta_{1} v+\alpha-p_{12}^{*}\right) d v+p_{12}^{*}= \\
& =\alpha+\beta_{1}
\end{aligned}
$$


with $C S_{i}^{L P}$ denoting the consumers' surplus of period $i$ and $\Pi_{i}^{L P}$ the profit of period $i$ under limit pricing. Likewise, the total surplus of the accommodating strategy obtains as

$$
\begin{aligned}
W^{A c c}= & C S_{1}^{A c c}+C S_{2}^{A c c}+\Pi_{1}^{A c c}+\Pi_{2}^{A c c} \\
= & \int_{0}^{1}\left(\beta_{1} v\right) d v \\
& +\int_{v_{1}\left(p_{12}^{*}, p_{22}^{*}\right)}^{1}\left(\beta_{2} v-p_{22}^{*}\right) d v+\int_{0}^{v_{1}\left(p_{12}^{*}, p_{22}^{*}\right)}\left(\beta_{1} v+\alpha-p_{12}^{*}\right) d v \\
& +p_{12}^{*}\left(\frac{p_{22}^{*}-p_{12}^{*}+\alpha}{\beta_{2}-\beta_{1}}\right)+p_{22}^{*}\left(1-\frac{p_{22}^{*}-p_{12}^{*}+\alpha}{\beta_{2}-\beta_{1}}\right)= \\
= & \frac{1}{18} \frac{5 \alpha^{2}+4 \alpha\left(\beta_{2}-\beta_{1}\right)+2\left(5 \beta_{1}+4 \beta_{2}\right)\left(\beta_{2}-\beta_{1}\right)}{\beta_{2}-\beta_{1}},
\end{aligned}
$$

with $C S_{i}^{A c c}$ denoting the consumers' surplus of period $i$ and $\Pi_{i}^{A c c}$ the profit of period $i$ under accommodation. The difference between the total surpluses obtains as:

$$
W^{A c c}-W^{L P}=\frac{1}{18} \frac{8\left(\beta_{2}-\beta_{1}\right)^{2}+5 \alpha^{2}-14 \alpha\left(\beta_{2}-\beta_{1}\right)}{\beta_{2}-\beta_{1}},
$$

which is negative whenever $\alpha \in\left(\frac{4}{5}\left(\beta_{2}-\beta_{1}\right), 2\left(\beta_{2}-\beta_{1}\right)\right)$ and positive otherwise. As an illustration, Figure 4 depicts the total surplus under limit pricing and accommodation as a function of the network intensity parameter $\alpha$ for $\beta_{2}=4$ and $\beta_{1}=1$.

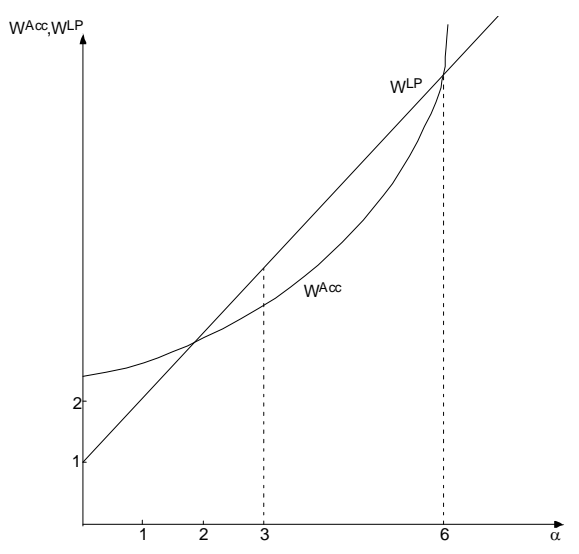

Figure 4: Welfare

When $\alpha \in\left(\frac{4}{5}\left(\beta_{2}-\beta_{1}\right), 2\left(\beta_{2}-\beta_{1}\right)\right)$, it would be better from the welfare point of view that only product 1 is available to consumers. However, at 
the equilibrium solution of period 2 , the incumbent chooses to accommodate entry when $\alpha \in\left(\left(\beta_{2}-\beta_{1}\right), 2\left(\beta_{2}-\beta_{1}\right)\right)$, thus making the suboptimal decision concerning its welfare consequences. In the referred domain, if total welfare is decomposed into its consumers' and firms' components, the presence of both products in the market leads to higher prices than in the limit pricing solution, which tends to reduce consumers' surplus. The positive difference in profits between accommodating and deterring does not compensate for the loss in consumers' surplus.

\section{Conclusion}

We have raised the question whether the existence of network effects could prevent the quality improvements resulting from the increase in the stand alone value. Even if this issue has been treated previously in the literature, it has never been examined in the context of a vertical product differentiation model. This exploration enables us to identify a very simple necessary and sufficient condition under which intrinsic quality improvements are effectively realized at equilibrium. This condition says that the intensity of the network effect should be smaller than twice the differential between the intrinsic qualities of the entrant's and incumbent's variants. We have also shown that for some combination of parameters, the monopolist's decision concerning quality improvement is suboptimal.

Several questions naturally arise from our work. One possibility would consist in keeping the model considered in this paper and analyzing the dynamics of entry assuming that the condition for quality improvement is always fulfilled. In this case, two products can simultaneously survive in the market in each period, giving rise to a sequence of duopolistic market structures.

\section{Appendix}

Proof (Lemma 1): Assume first that the market is uncovered; the profit function is then given by

$$
\pi_{t o t}\left(p_{11}\right)=\frac{\beta_{2}\left(\beta_{1}\left(\beta_{2}-\beta_{1}\right)+\alpha\left(1-\frac{p_{11}}{\beta_{1}}\right)\left(2 \beta_{2}-\beta_{1}\right)\right)^{2}}{\left(4 \beta_{2}-\beta_{1}\right)^{2}\left(\beta_{2}-\beta_{1}\right) \beta_{1}}+p_{11}\left(1-\frac{p_{11}}{\beta_{1}}\right) .
$$


This function is quadratic in $p_{11}$ and concave (resp. convex) when $\alpha$ belongs to the domain $(0, \hat{\alpha})$ with $\hat{\alpha}=\frac{\beta_{1}}{\beta_{2}} \sqrt{\beta_{2}\left(\beta_{2}-\beta_{1}\right)} \frac{4 \beta_{2}-\beta_{1}}{2 \beta_{2}-\beta_{1}}$ (resp. $\left.(\hat{\alpha}, \infty)\right)$. Whenever $4 \beta_{2}-13 \beta_{1}>0, \hat{\alpha}<\beta_{2}-\beta_{1}$ and thus in the relevant domain the function $\pi_{t o t}\left(p_{11}\right)$ is convex. The maximum must obtain at one of the boundaries of the admissible domain $\left[0, \beta_{1}\right]$ for $p_{11}$. Comparing these profits at the two extreme values of the domain, it is easily seen that $\pi_{t o t}\left(p_{11}\right)$ is always maximal at $p_{11}^{*}=0$.

Now assume that $p_{11}$ entails a covered market in period 2 . Then the incumbent chooses $p_{11}$ that maximizes:

$$
\Pi_{\text {total }}\left(p_{11}\right)=\frac{1}{9} \frac{\left(\alpha\left(1-\frac{p_{11}}{\beta_{1}}\right)+\beta_{2}-\beta_{1}\right)^{2}}{\beta_{2}-\beta_{1}}+p_{11}\left(1-\frac{p_{11}}{\beta_{1}}\right) .
$$

This function is convex whenever $\alpha>3 \sqrt{\beta_{1}\left(\beta_{2}-\beta_{1}\right)}$. In that case is easily shown that the maximum is attained at $p_{11}=0$. Assume first that $3 \sqrt{\beta_{1}\left(\beta_{2}-\beta_{1}\right)}<$ $\beta_{2}-\beta_{1}$, in which case $\beta_{2}>10 \beta_{1}$. Then for $\alpha \in\left[\beta_{2}-\beta_{1}, 2\left(\beta_{2}-\beta_{1}\right)\right]$, the profit function is convex and $p_{11}=0$. Now assume that $\beta_{2}-\beta_{1}<$ $3 \sqrt{\beta_{1}\left(\beta_{2}-\beta_{1}\right)}<2\left(\beta_{2}-\beta_{1}\right)$, in which case $\frac{13}{4} \beta_{1}<\beta_{2}<10 \beta_{1}$. Then for $\alpha \in\left[3 \sqrt{\beta_{1}\left(\beta_{2}-\beta_{1}\right)}, 2\left(\beta_{2}-\beta_{1}\right)\right]$ the function is convex and $p_{11}=0$. For $\alpha \in\left[\beta_{2}-\beta_{1}, 3 \sqrt{\beta_{1}\left(\beta_{2}-\beta_{1}\right)}\right]$ the profit function is concave and its first derivative vanishes at $p_{11}=\frac{1}{2} \beta_{1} \frac{2 \alpha\left(\alpha+\left(\beta_{2}-\beta_{1}\right)\right)-9 \beta_{1}\left(\beta_{2}-\beta_{1}\right)}{\alpha^{2}-9 \beta_{1}\left(\beta_{2}-\beta_{1}\right)}$, which is negative in the relevant domain of parameters. Accordingly, the optimal value of $p_{11}$ is once again 0. QED

\section{References}

[1] Baake, P., and A. Boom, 1999, 'Vertical Product Differentiation, Network Externalities, and Compatibility Decisions', mimeo, Humboldt University

[2] Bental, B. and M. Spiegel, 1995, 'Network competition, product quality, and market coverage in the presence of network externalities', The Journal of Industrial Economics, 43, 197-208

[3] Farrell, J. and G. Saloner, 1986, 'Installed base and compatibility: innovation, product preannouncements and predation', The American Economic Review, 7(5), 940-955 
[4] Fudenberg, D., and J. Tirole, 2000, 'Pricing a Network Good to Deter Entry', Journal of Industrial Economics, 48, 373-390

[5] Gabszewicz, J.J., L. Pepall, and J.-F. Thisse, 1992, 'Sequential Entry with Brand Loyalty Caused by Consumer Learning-by-Using, Journal of Industrial Economics, 40, 397-416

[6] Garcia, F., 2005, 'When does a monopoly improve its quality?', mimeo CORE.

[7] Katz, M. and C. Shapiro, 1992, 'Product introduction with network externalities, The Journal of Industrial Economics, 40, 55-83

[8] Rohlfs, J. (1974), "A theory of interdependent demand for a communication service", Bell Journal of Economics, 5, 16-37

[9] Shy, O., 1996, 'Technology Revolutions in the Presence of Network Externalities', International Journal of Industrial Organization, 14(6), 785-800 
Département des Sciences Économiques de l'Université catholique de Louvain

Institut de Recherches Économiques et Sociales

Place Montesquieu, 3

1348 Louvain-la-Neuve, Belgique 